\title{
Can commonly used antibiotics disrupt formation of new memories?
}

\author{
CHARLES D. OSBORN and FRANK A. HOLLOWAY \\ University of Oklahoma Health Sciences Center, Oklahoma City, Oklahoma
}

\begin{abstract}
Male Sprague-Dawley rats were injected $0.5 \mathrm{~h}$ prior to training in a passive-avoidance task with chloramphenicol, a protein synthesis inhibitor. The rats were retested 7 days later and found to have impaired memory.
\end{abstract}

For more than three decades, we have known that injections of certain protein synthesis inhibitors can induce amnesia in experimental animals. For example, pretraining injections of cycloheximide (CXM) have no effect on the acquisition or learning of a new habit, but exert long-term amnestic effects (i.e., impair retention) (Geller, Robustelli, Barondes, Cohen, \& Jarvik, 1969). Furthermore, studies also have shown that posttraining injections of several hormones can facilitate retention of newly acquired habits or, in some cases, reverse the amnestic effects produced by protein synthesis inhibition (Judge \& Quartermain, 1982; Quartermain, Freedman, Botwinick, \& Gutwein, 1977). Finally, analogs of certain of these hormones, which are antagonists to the hormones themselves, have been found to impair retention (Ettenberg, Moal, Koob, \& Bloom, 1983). The nature of the interaction between hormones and protein synthesis is obviously complex, with probable multiple modes of action (e.g., synthesis, metabolism, etc.).

The latter data clearly indicate that long-term memory formation requires time and that, during the immediate postacquisition period, the memory trace is vulnerable. McGaugh (1983) stated that "the fact that newly acquired memories are so easily influenced suggests that memory storage processors may be modulated by endogenous physiological systems activated by experiences" (p. 161). One model, seeking to describe the interaction between memory, hormones, and protein synthesis inhibition, attributes information storage (memory) functions to brain cholinergic systems and retrieval/ integration (learning) functions to brain adrenergic systems (Barraco \& Stettner, 1976). Another model suggests that "the sequence of underlying memory storage involves the modulation of 'memory cells' by other brain systems ... findings suggest that these modulating systems may require the influence of hormones" (McGaugh, 1983, p. 171).

Virtually all of the protein synthesis inhibition and memory studies have been directed at basic experimental questions regarding the biological basis of memory.

Frank A. Holloway's mailing address is: University of Oklahoma Health Sciences Center, Department of Psychiatry \& Behavioral Sciences, P.O. Box 26901, Oklahoma City, OK 73190.
However, a little reflection suggests at least one relevant clinical implication. Many commonly used antibiotics for human bacterial infections act by inhibiting protein synthesis [e.g., tetracycline, chloramphenicol (CAP)]. One possible side effect mentioned for some of these compounds is that of mental confusion (Weinstein, 1980). This experiment attempted to explore the possibility that such antibiotics may also affect memory formation and/or storage in some manner.

Most of the research on protein synthesis inhibition and memory has employed broad-spectrum antibiotics with very potent and generalized effects. For example, CXM blocks protein synthesis in all parts of the cell. Little work has been done with antibiotics that may have more specific or restricted effects. In selecting a representative therapeutic drug for this experiment, tetracycline was ruled out, since it ordinarily does not pass the blood-brain barrier unless a CNS infection is present. However, one drug that seemed to be appropriate was CAP. CAP is used in the treatment of some gram-negative bacterial infections but has no trouble crossing the blood-brain barrier. CAP inhibits protein synthesis by acting on the $50 \mathrm{~S}$ ribosomal subunit and suppressing peptide bond formation by peptide transferase (Weinstein, 1980). CAP, however, appears to affect mammalian cells (particularly reticulocytes) in a manner different from that in which it affects bacteria. It is hypothesized that mitochondrial ribosomes in mammals resemble bacterial ribosomes (both about 70S) more than do the $80 \mathrm{~S}$ cytoplasmic ribosomes (Wheeldon \& Lehninger, 1966). Since mitochondria are present in such large quantities in the neural synapse, inhibition of mitochondrial protein synthesis has been found to have a profound effect on nerve terminal development and functioning (Bertolini \& Poggioli, 1981).

This experiment investigated the possibility that CAP would disrupt long-term memory formation using a standard rat model of memory (one-trial, passive-avoidance task) (McGaugh, 1983). Positive results (i.e., retention impairment by CAP) may indicate the need to consider another class of undesirable side effects (memory disruption) that could result from the therapeutic use of this or related drug(s). 


\section{METHOD}

\section{Subjects}

Male Sprague-Dawley rats (Sasco, Inc.) were used as subjects. The animals were housed two per cage and maintained on ad-lib food and water. They were adapted to the 12-h light/dark cycle for 10 days prior to the beginning of the experiment.

\section{Drugs}

Two protein synthesis inhibitors were used in this study: CXM and CAP. CAP is used to treat gram-negative bacterial infection, but is not recommended for routine therapy because of possible side effects (particularly reticulocytopnea). CAP is ineffective when injected intramuscularly; hence, it was injected intraperitoneally in a dose of $250 \mathrm{mg} / \mathrm{kg}$. CXM was examined for comparison purposes at a suggested dosage of $1 \mathrm{mg} / \mathrm{kg}$ (LeBlanc, Matsunaga, \& Kalant, 1976). The control injection (PGS) was a $50 \%$ propylene glycol and $50 \%$ normal saline mixture made necessary as a compromise between the solubility of CAP and the viscosity of the propylene glycol.

\section{Apparatus/Task}

The experimental task was a standard one-trial passive-avoidance task. This procedure involved giving the animal a $0.1-\mathrm{W}$ (constantvoltage) footshock (maximum duration of $10 \mathrm{sec}$ ) when it first entered the dark compartment of a two-compartment apparatus and testing for (passive) avoidance of this previously shocked dark compartment on a subsequent occasion. A detailed description of the apparatus and procedure for its use is found elsewhere (Holloway \& Wansley, 1973).

\section{Procedures}

Forty-eight animals in three experimental groups were given one training session and then tested for retention (no shock) 7 days later. The test session lasted $10 \mathrm{~min}$ or until the animal entered the dark (shock) chamber. All the animals received injections of one of the three drug or control solutions $0.5 \mathrm{~h}$ prior to the training session. During the training session, the following measures were recorded: activity in the lighted compartment (SBA, startbox activity), step-through latency (STL, seconds to enter shock compartment), and escape latency (ES LAT, seconds to reenter the start compartment after shock). During the test session, only SBA and STL were measured again. Also, the weight loss of each animal was measured $24 \mathrm{~h}$ postinjection. A $\mathrm{U}$ test was performed on all measurements because of nonnormality of data distributions.

\section{RESULTS}

Figure 1 shows that the mean STLs and SBAs for the three experimental groups were not significantly different during the training session. Also, the SBAs for the three groups were not significantly different during the test session. However, during the test session, the mean STLs for the CAP and CXM groups were significantly lower than the mean STL for the PGS (control) group $(\mathrm{z}=1.86, \mathrm{p}<.0314$, and $\mathrm{z}=1.83, \mathrm{p}<.0336$, respectively). Although there was no significant difference between the mean training ES LATs of the CAP $(1.5 \mathrm{sec})$ and PGS $(1.4 \mathrm{sec})$ groups, a significant difference between the mean ES LATs of the CXM $(2.0 \mathrm{sec})$ and PGS groups was found $(z=1.98, p<.0239)$.

Both the CAP (14 g) and CXM (12 g) groups had significantly greater weight losses than did the PGS $(8 \mathrm{~g})$ group $(\mathrm{z}=2.72, \mathrm{p}<.0033$, and $\mathrm{z}=1.92, \mathrm{p}<.0274$, respectively).
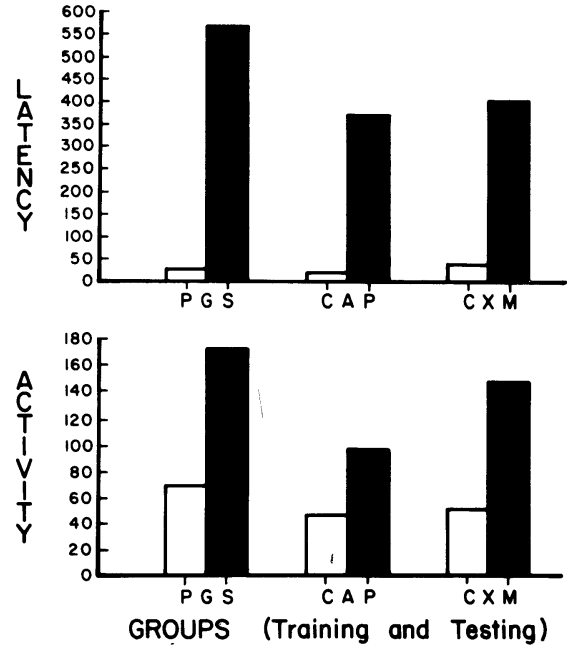

Figure 1. Mean step-through latency (STL, in seconds) (top) and mean startbox activity (SBA, in counts per minute) (bottom) at training (open bar) and testing (solid bar) sessions.

\section{DISCUSSION}

The results of this experiment seem to indicate that CAP may disrupt the formation of long-term memory. It must be considered, however, that these results may be due to some mechanism other than inhibition of protein synthesis. Although severe side effects, such as aplastic anemia, are of primary concern during therapeutic use of CAP, there are several other minor side effects. Dosages as low as $50 \mathrm{mg} / \mathrm{kg}$ in humans are known to cause headaches, mild depression, mental confusion, and delerium (Physicians' Desk Reference, 1984). These side effects and the fact that CAP-injected animals in this study lost a significant amount of weight postinjection could indicate that the results may have been due to failure to learn the task rather than disruption of long-term memory.

If sickness or confusion played a role in the animal's behavior, then it would be assumed that the mean STL and ES LAT for the CAP group should be significantly different from those for the PGS group. As shown in the results, there was no significant difference in these measures for the two groups. Furthermore, mean ES LAT and weight loss for the CXM group were significantly higher than for the controls. CXM is known to cause illness even at a dosage of $1 \mathrm{mg} / \mathrm{kg}$, but its protein synthesis inhibition, not the induced illness, appears responsible for the long-term memory disruption (Geller et al., 1969).

A final problem that may have contributed to the results was the adversity of the experiment. Propylene glycol, which was used as the vehicle for all injections, caused a painful and violent reaction in all animals for several seconds postinjection. Also, the shock delivered during the training session may have been adversive enough to make the task too easy or too frightening to the animal.

Further confirmation that CAP disrupts long-term memory by protein synthesis inhibition will require a more detailed study with higher drug dosages at various time intervals. Perhaps a less aversive shock or a one-trial appetitive task would be in order. It would also be of interest to ascertain whether or not the effects of CAP can be reversed by the administration of the various hormones used in previous studies (Judge \& Quartermain, 1982; Quartermain et al., 1977). If CAP is found to disrupt long-term memory by protein synthesis inhibition, another class of undesirable side effects may be added to an already long list. If so, tetracycline, which acts to inhibit protein synthesis via similar 
biochemical mechanisms, should also be studied (perhaps by an intracranial procedure or an artificially induced CNS infection). The use of CAP in memory studies may have implications in the therapeutic use of antibiotics in humans and, because of its possible specificity, may lead to more answers to the question of the role of protein synthesis in the formation of new memories.

\section{REFERENCES}

Barraco, R. A., \& Stettner, L. J. (1976). Antibiotics and memory. Psychology Bulletin, 88, 242-302.

Bertolini, A., \& Poggioli, R. (1981). Chloramphenicol administration during brain development: Impairment of avoidance learning in adulthood. Science, 213, 238-239.

Ettenberg, A., Moal, M. L., Коoв, G. F., \& Bloom, F. E. (1983). Vasopressin potentiation in the performance of a learned appetitive task: Reversal by a pressor antagonist analog of vasopressin. Pharmacology, Biochemistry and Behavior, 18, 645-647.

Geller, A., Robustelli, F., Barondes, S. H., Cohen, H. D., \& JARVIK, M. E (1969). Impaired performance by post-trial injections of cycloheximide in a passive avoidance task. Psychopharmacologia, 14, 371-376.

Holloway, F. A., \& Wansley, R. (1973). Multiphasic retention deficits at periodic intervals after passive-avoidance learning. Science, 180, 208-210.
Judge, M. E., \& Quartermain, D. (1982). Alleviation of anisomycin-induced amnesia by pre-test treatment with lysine vasopressin. Pharmacology, Biochemistry and Behavior, 16, 463-466.

LeBlanc, A. E., Matsunaga, M., \& Kalant, H. (1976). Effects of frontal polar cortical ablation and cycloheximide on ethanol tolerance in rats. Pharmacology, Biochemistry and Behavior, 4, 175-179.

McGaugh, J. L. (1983). Preserving the presence of the past. American Psychologist, 38, 161-174.

Physicians' Desk Reference. (38th ed., pp. 1451-1453) (1984). Oradell, NJ: Medical Economics Company.

Quartermain, D., Freedman, S., Botwinick, C. Y., \& Gutwein, B. M. (1977). Reversal of cycloheximide-induced amnesia by adrenergic receptor stimulation. Pharmacology, Biochemistry and Behavior, 7, 259-267.

Weinstein, L. (1980). Chloramphenicol. In L. S. Goodman \& A. Gilman (Eds.), The pharmacological basis of therapeutics (pp. 1183-1200). New York: Macmillan.

Wheeldon, L. W., \& Lehninger, A. L. (1966). Energy-linked synthesis and decay of membrane proteins in isolated rat liver biochemistry. Biochemistry, 5, 3533-3545

(Manuscript received for publication February 27, 1984.) 